\title{
Molecular Basis of Autosomal Dominant Neurohypophyseal Diabetes Insipidus Cellular Toxicity Caused by the Accumulation of Mutant Vasopressin Precursors within the Endoplasmic Reticulum
}

Mika Ito, J. Larry Jameson, and Masafumi Ito

Division of Endocrinology, Metabolism, and Molecular Medicine, Northwestern University Medical School, Chicago, Illinois 60611

\begin{abstract}
Mutations in the arginine vasopressin (AVP) gene cause autosomal dominant familial neurohypophyseal diabetes insipidus (FNDI). The dominant inheritance pattern has been postulated to reflect neuronal toxicity of the mutant proteins, but the mechanism for such cytotoxicity is unknown. In this study, wild-type or several different mutant $A V P$ genes were stably expressed in neuro2A neuroblastoma cells. When cells were treated with valproic acid to induce neuronal differentiation, each of the mutants caused reduced viability. Metabolic labeling revealed diminished intracellular trafficking of mutant AVP precursors and confirmed inefficient secretion of immunoreactive AVP. Immunofluorescence studies demonstrated marked accumulation of mutant AVP precursors within the endoplasmic reticulum. These studies suggest that the cellular toxicity in FNDI may be caused by the intracellular accumulation of mutant precursor proteins. (J. Clin. Invest. 1997. 99:1897-1905.) Key words: neurohypophyseal diabetes insipidus - autosomal dominant inheritance $\cdot$ endoplasmic reticulum - genetic mutation $\bullet$ neuronal toxicity
\end{abstract}

\section{Introduction}

Arginine vasopressin (AVP) $)^{1}$ is a hormone that controls serum osmolality by altering renal clearance of free water $(1,2)$ and is derived from a precursor protein that is synthesized in the magnocellular neurons of the hypothalamus. PreproAVP is converted to proAVP by removal of its signal peptide and the addition of carbohydrate side chains. Additional posttranslational processing occurs within neurosecretory vesicles during

Address correspondence to J. Larry Jameson, Division of Endocrinology, Metabolism, and Molecular Medicine, Northwestern University Medical School, Tarry 15-709, 303 E. Chicago Avenue, Chicago, IL 60611. Phone: 312-503-0469; FAX: 312-503-0474; E-mail: ljamelson@ dnwu.edu

Received for publication 17 December 1996 and accepted in revised form 3 February 1997.

1. Abbreviations used in this paper: AVP, arginine vasopressin; CAT, chloramphenicol acetyltransferase; EndoH, endoglycosidase H; ER, endoplasmic reticulum; FNDI, familial neurohypophyseal diabetes insipidus; MTS, 3-(4,5-dimethylthiazol-2-yl)-5-(3-carboxymethoxyphenyl)-2-(4-sulfophenyl)-2H-tetrazolium, inner salt; NP, neurophysin; VPA, valproic acid; WT, wild-type.

J. Clin. Invest.

(C) The American Society for Clinical Investigation, Inc.

0021-9738/97/04/1897/09 \$2.00

Volume 99, Number 8, April 1997, 1897-1905 transport to axon terminals in the posterior pituitary, yielding AVP, neurophysin (NP), and glycoprotein (3). The $A V P$ gene is located on chromosome 20 (4), and consists of 3 exons. Exon 1 encodes the signal peptide, AVP, and the aminoterminal region of NP. Exon 2 gives rise to the central region of NP, and exon 3 contains the carboxyterminal region of NP and glycoprotein (5).

Familial neurohypophyseal diabetes insipidus (FNDI) is caused by mutations in the $A V P$ gene (6). The disorder is transmitted in an autosomal dominant manner, and typically presents in early childhood, apparently reflecting the progressive loss of AVP secretion in response to increased serum osmolality $(7,8)$. Numerous mutations within the $A V P$ gene have been identified recently in patients with FNDI $(6,9-18)$. The mutations are distributed throughout the precursor protein, and include missense mutations within the signal sequence $(10,12,13,17)$, the AVP peptide (17a), and the NP domain $(6,9,11,14-16,18)$. In addition, nonsense mutations have been reported within the NP domain that result in a truncated version of the precursor protein $(15,16)$.

The mechanism by which these $A V P$ gene mutations cause FNDI is unknown, and the autosomal dominant inheritance of the disorder is particularly intriguing. Autopsy studies in patients with FNDI have suggested a paucity of AVP-producing neurons in the hypothalamus (19-21), and this has led to the suggestion that the mutations exert a cytotoxic effect. Consistent with the loss of AVP neurons, some patients with FNDI lack the characteristic bright spot on magnetic resonance imaging of the posterior pituitary (17).

In a previous study using an in vitro translation system, we found that a mutation in the signal sequence (Ala to Thr at amino acid $-1, \mathrm{~A}(-1) \mathrm{T}$ ) caused inefficient cleavage of the signal peptide (10). In this study, several mutant $A V P$ genes were stably expressed in neuro2A neuroblastoma cells (22) that have been shown to process hormone precursors into authentic maturation products (23-25). Cell lines expressing mutant $A V P$ genes exhibited impaired intracellular trafficking of AVP precursors and reduced viability. The accumulation of mutant AVP precursors in the endoplasmic reticulum (ER) provides a potential cause of neuronal cell death in patients with FNDI.

\section{Methods}

Plasmid constructions. Mutations analyzed in this study include G57S (6), A(-1)T (10), $\Delta$ E47 (11), and C67X (15) (see Fig. $1 A$ ). Mutant cDNAs for these mutations were synthesized from the human wild-type $A V P$ cDNA (10) by the PCR as described previously (6). After mutagenesis, the entire cDNA sequence was verified by the dideoxy-mediated chain termination method (26). The sizes of G57S, $\mathrm{A}(-1) \mathrm{T}$ and $\Delta \mathrm{E} 47 \mathrm{cDNAs}$ are $600 \mathrm{bp}$, whereas the C67X cDNA is smaller (400 bp), because it does not contain the DNA sequence en- 
coding the region after the stop codon. These cDNAs, along with the control, chloramphenicol acetyltransferase (CAT), were subcloned into the $\mathrm{pRc} / \mathrm{RSV}$ vector that also contains the neomycin resistance gene (Invitrogen Corp., San Diego, CA).

Cell culture and transfection. Neuro2A cells were obtained from the American Type Culture Collection (CCL 131; Rockville, MD) and were grown in MEM supplemented with $10 \% \mathrm{FBS}$ in a $5 \% \mathrm{CO}_{2}$ atmosphere at $37^{\circ} \mathrm{C}$. Cells were transfected by using Transfectam (Promega Corp., Madison, WI) according to the instructions of the manufacturer. Cells were selected in media containing $0.3 \mathrm{mg} / \mathrm{ml}$ G418 (GIBCO BRL, Gaithersburg, MD) for $2 \mathrm{wk}$. Stable clones were isolated, expanded, and tested for the production of AVP precursors or CAT proteins. After selection, the concentration of G418 in the medium was reduced to $0.2 \mathrm{mg} / \mathrm{ml}$. In some experiments, cells were treated with $1 \mathrm{mM}$ valproic acid (VPA) (Sigma Chemical Co., St. Louis, $\mathrm{MO})$ to induce differentiation.

Northern blot analyses. Total RNA was isolated from stable clones using an RNA extraction kit (Qiagen, Chatsworth, CA). Total RNA $(10 \mu \mathrm{g})$ was subjected to agarose gel electrophoresis and transferred to Hybond $\mathrm{N}+$ membranes (Amersham Corp., Arlington Heights, IL). A full length 600 bp human $A V P$ cDNA was radiolabeled using the Prime-it random primer labeling kit (Stratagene Inc., La Jolla, CA). The membrane was hybridized with ${ }^{32} \mathrm{P}$-labeled probe in a rapid hybridization buffer (Amersham Corp.) followed by washing and autoradiography.

CAT assays and Western blot analyses. The CAT activity in stably transfected, G418-resistant clones, was determined using the CAT enzyme assay system (Promega Corp.). Cell extracts were incubated in a reaction mix containing ${ }^{14} \mathrm{C}$-chloramphenicol (ICN Biochemicals Inc., Irvine, CA) and $n$-butyryl coenzyme A. The reaction was extracted with xylene and the organic phase containing $n$-butyryl chroramphenicol was quantified using a scintillation counter. For detection of CAT protein on Western blots, cell extracts were subjected to $10 \%$ SDS-polyacrylamide gel electrophoresis. Separated proteins were electrotransferred to Hybond ECL (Amersham Corp.). Membranes were blocked in 3\% skim milk, probed with anti-CAT digoxigenin $(10 \mu \mathrm{g} / \mathrm{ml})$ and incubated with antidigoxigenin Fab fragment conjugated to peroxidase $(300 \mathrm{mU} / \mathrm{ml})$ (Boehringer Mannheim Biochemicals, Indianapolis, IN). Subsequently, proteins were detected using the enhanced chemiluminescence detection system (Amersham Corp.).

Metabolic labeling and pulse-chase analyses. For continuous labeling, cells $\left(2 \times 10^{5}\right)$ plated in 6-well plates were incubated for $18 \mathrm{~h}$ in $1 \mathrm{ml}$ of MEM containing $100 \mu \mathrm{Ci}$ of Expre ${ }^{35} \mathrm{~S}^{35} \mathrm{~S}$ protein labeling mix (a mixture of ${ }^{35} \mathrm{~S}$-methionine and ${ }^{35} \mathrm{~S}$-cysteine) (Dupont-NEN, Boston, MA). The culture medium was harvested and cells were lysed in $1 \mathrm{ml}$ of buffer A $(50 \mathrm{mM}$ Tris $\mathrm{pH} 8.0,0.5 \%$ deoxycholic acid, $150 \mathrm{mM} \mathrm{NaCl}, 1 \%$ Triton X-100, 0.1\% SDS, $1 \mathrm{mM}$ phenylmethylsulfonyl fluoride, $1 \mu \mathrm{g} / \mathrm{ml}$ aprotinin, $1 \mu \mathrm{g} / \mathrm{ml}$ leupeptin, $1 \mu \mathrm{g} / \mathrm{ml}$ pepstatin A). To the culture medium, $1 \mathrm{ml}$ of $2 \times$ buffer A was added. Polyclonal anti-AVP $(2.5 \mu \mathrm{l})$ or NP $(2.5 \mu \mathrm{l})$ antibody (ICN Biochemicals Inc.) and protein A agarose $(20 \mu \mathrm{l})$ (Santa Cruz Biotechnology, Inc., Santa Cruz, CA) were added to $1 \mathrm{ml}$ of the culture medium and $0.5 \mathrm{ml}$ of cell lysates. After extensive washing, whole immunoprecipitates were boiled in SDS sample buffer and separated using 16.5\% SDS-polyacrylamide gels. Gels were analyzed using a phosphorimager (Fuji, Stamford, CT). For pulse-chase analyses, cells $\left(2 \times 10^{5}\right)$ plated in 6-well plates were labeled for $0.5 \mathrm{~h}$ with $100 \mu \mathrm{Ci}$ of Expre $^{35} \mathrm{~S}^{35} \mathrm{~S}$ protein labeling mix in $0.5 \mathrm{ml}$ of methionine- and cysteine-free MEM and chased using $1 \mathrm{ml}$ of complete MEM. In some experiments, immunoprecipitates were treated with endoglycosidase $\mathrm{H}$ (Endo $\mathrm{H}$ ) according to the manufacturer's instructions (New England BioLabs, Beverly, MA).

Measurement of AVP immunoreactivity. Stably transfected cells $\left(2 \times 10^{5}\right)$ were plated in 6-well plates. $2 \mathrm{~d}$ later, cells were washed with PBS and fed with $2 \mathrm{ml}$ of MEM. $24 \mathrm{~h}$ later, the culture medium was harvested. After washing, cells were lysed and the protein concentration of cell lysates was determined by the Bradford protein assay (Bio-Rad, Hercules, CA). The AVP immunoreactivity in the me- dium was measured using a radioimmunoassay kit (AVP-RIA kit; Mitsubishi Petrochemical Co. Ltd., Tokyo, Japan).

Cell growth and apoptosis assays. The number of viable cells in 96-well plates was determined using the Celltiter 96 aqueous nonradioactive cell proliferation assay (Promega Corp.). The assay consists of a tetrazolium compound (3-(4,5-dimethylthiazol-2-yl)-5-(3-carboxymethoxyphenyl)-2-(4-sulfophenyl)-2H-tetrazolium, inner salt [MTS]) and an electron coupling reagent (phenazine methosulfate; PMS). MTS is bioreduced by dehydrogenase enzymes present in metabolically active cells and produces a formazan that is soluble in culture medium. The combined MTS/PMS solution $(20 \mu \mathrm{l})$ was added to 100 $\mu \mathrm{l}$ of the culture medium in each well. After $5 \mathrm{~h}$ at $37^{\circ} \mathrm{C}$ in a humidified $5 \% \mathrm{CO}_{2}$ atmosphere, the absorbance of the formazan at $490 \mathrm{~nm}$ and the absorbance at $630 \mathrm{~nm}$ was recorded using an ELISA plate reader (Bio-Tek, Winooski, VT). For DNA fragmentation analyses, genomic DNA was extracted from cells and analyzed on a $1.5 \%$ agarose gel. DNA was stained with ethidium bromide and visualized under ultraviolet light. For TUNEL (terminal deoxynucleotidyl transferase (TdT)-mediated dUTP nick-end-labeling) assays, cells were plated on 8-well chamber slides and tested for the presence of apoptotic cells using the apoptosis detection system (Promega Corp.). This system detects fragmented DNA in apoptotic cells by catalytically incorporating fluorescein-12-dUTP at the 3 '-OH DNA ends using TdT. After the TUNEL reaction, the fluorescein-12-dUTP labeled DNA was visualized by fluorescence microscopy.

Indirect immunofluorescence studies. Cells were grown on 8-well chamber slides and fixed with $4 \%$ paraformaldehyde in $0.01 \mathrm{M}$ PBS for $15 \mathrm{~min}$. Permeabilization was performed by incubating the cells for $30 \mathrm{~min}$ in PBS containing 5\% preimmune goat serum and $0.1 \%$ Triton X-100. Cells were then incubated with primary antibody in PBS containing $3 \%$ BSA. The primary antibodies used were anti-NP antibody (diluted 1:250) or anti-KDEL antibody (1 $\mu \mathrm{g} / \mathrm{ml}$ ) (Affinity Bioreagents, Golden, $\mathrm{CO}$ ). After washing, cells were incubated with fluorescein-conjugated secondary antibody against rabbit IgG (diluted 1:1000) (Pierce, Rockford, IL) in PBS containing 3\% BSA. After washing, cells were visualized and photographed using a fluorescence microscope (Carl Zeiss, Thornwood, NY).

\section{Results}

Identification of stably transfected neuro2 A cell lines expressing $A V P$ mutants. Wild-type (WT) or several different naturally occurring AVP mutants (G57S [6], A(-1)T [10], $\Delta \mathrm{E} 47$ [11], C67X [15]) (Fig. $1 A$ ) were stably transfected into neuro2A cells. As a control, $C A T$ cDNA was transfected in parallel with the AVP constructs. After selection in G418, individual clonal cell lines for each construct were characterized for expression of AVP precursors or CAT protein. As shown in Fig. $2 A$, selected cell lines expressed similar levels of $A V P$ mRNA. The WT, G57S, A(-1)T, and $\Delta \mathrm{E} 47$ each expressed a $0.6-\mathrm{kb}$ transcript, and the C67X mutant expressed a 0.4-kb transcript, consistent with the cDNA size in the expression vector. No $A V P$ mRNA was detected in cells expressing CAT protein, confirming that there is no endogenous AVP production in this cell line.

Cell lines were also characterized for protein expression. Stable clones expressing CAT proteins were identified using CAT assays, and Western blot studies confirmed expression of the 26-kD CAT protein (data not shown). Analyses of AVP precursors were performed by immunoprecipitation of metabolically labeled proteins. Cell lines were labeled continuously and extracts were subjected to immunoprecipitation using an anti-NP antibody. Similar amounts of the expected 21-kD AVP precursor protein (10) were found in each of the selected cell lines stably transfected with WT, G57S, A(-1)T, and $\Delta \mathrm{E} 47$ 


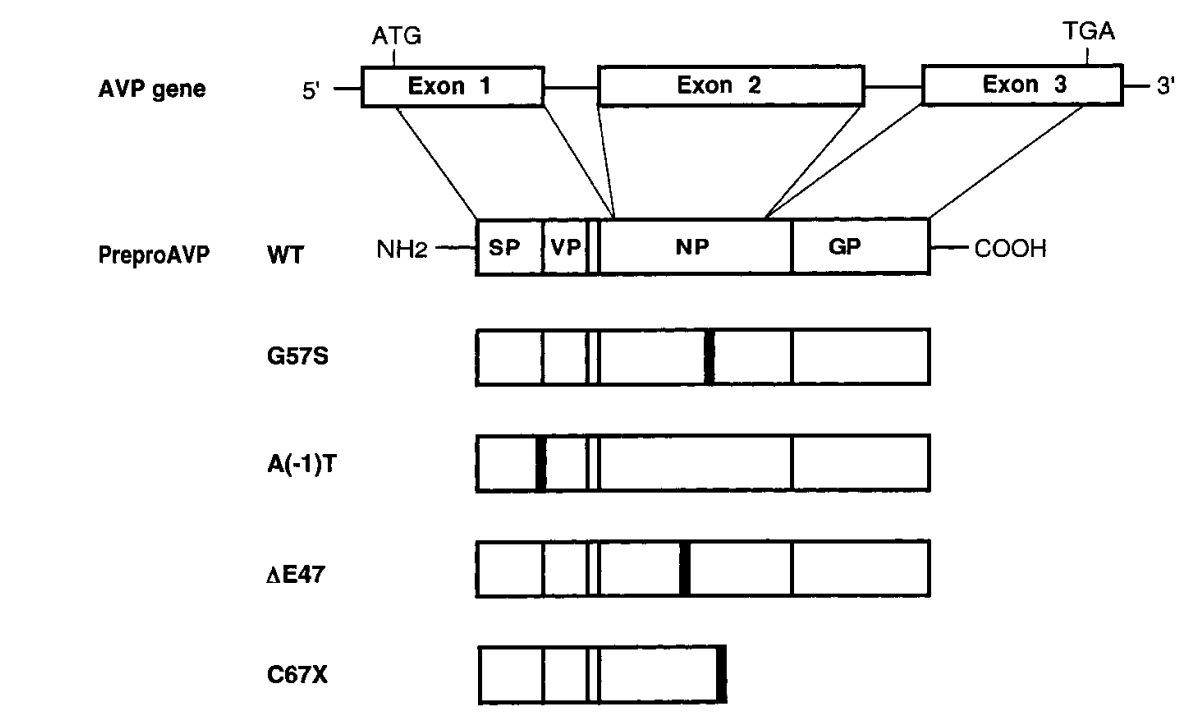

B
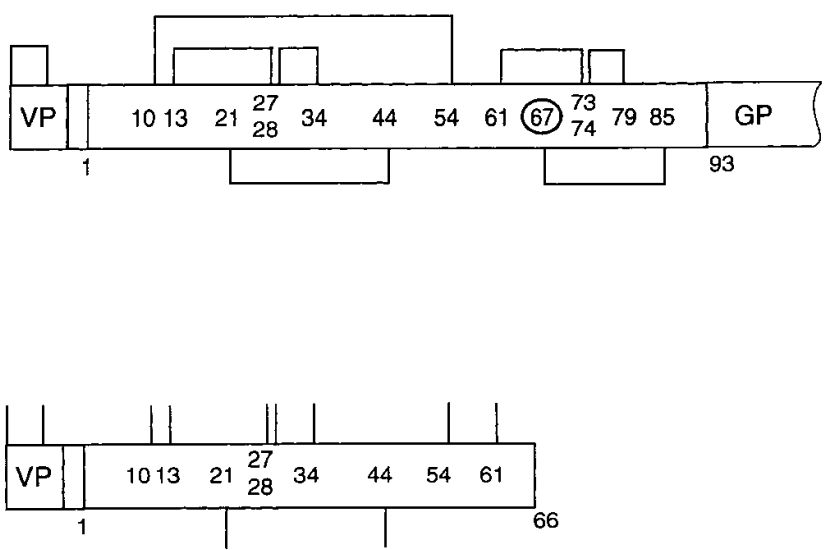

Figure 1. Schematic representation of AVP mutants. $(A)$ The structure of the $A V P$ gene and the encoded precursor peptide is depicted along with the four AVP mutations examined in this study. The $(A(-1) T)$ mutation in exon 1 replaces Ala at the carboxyterminus of the signal peptide ( -1 position) with Thr. Mutations in exon 2 include a Ser for Gly at amino acid position 57 (G57S), a deletion of Glu at position $47(\Delta E 47)$, and a premature termination at position $67(C 67 X)$ ). $S P$, signal peptide; $V P$, AVP; $N P$, neurophysin; $G P$, glycoprotein. $(B)$ The locations of the cysteine residues and disulfide bonds within the NP domain are shown (27). Numbers indicate the position of cysteine residues. The C67X mutation at amino acid position 67 (shown by circle) gives rise to a truncated precursor which lacks 5 out of 14 cysteine residues within the NP domain.
cDNAs (Fig. 2 B). The C67X mutation results in premature termination and an elimination of 5 out of 14 cysteine residues within the NP domain (27) (Fig. $1 B$ ). In this cell line, the antiNP antibody immunoprecipitated a 9-kD protein, which likely corresponds to a prematurely terminated precursor with the signal peptide removed (78 amino acids). The level of expression of the truncated protein cannot be compared directly with the other mutants because the number of radiolabeled amino acids is reduced, and the efficiency of immunoprecipitation may be altered.

The amount of immunoreactive AVP secreted into the medium is shown in Fig. $2 C$. The anti-AVP antibody reacts with precursors and intermediate forms, as well as fully processed AVP. The amount of immunoreactivity in the medium of the stably transfected cell lines was: CAT, 0.05 \pm 0.03 ; WT, $2.77 \pm 0.34 ; \quad$ G $57 \mathrm{~S}, 0.50 \pm 0.07 ; \mathrm{A}(-1) \mathrm{T}, 0.74 \pm 0.14 ; \quad \Delta \mathrm{E} 47$, $0.18 \pm 0.02$; C67X, $0.70 \pm 0.13 \mathrm{pg} / \mu \mathrm{g}$ of cell protein per $24 \mathrm{~h}$. Thus, the WT clone secreted immunoreactive AVP at much greater levels than any of the four mutants, even though the cell lines were selected based upon similar amounts of AVP mRNA and precursor proteins.

Cytotoxicity of AVP mutants. Since FNDI has been hypothesized to involve progressive loss of AVP-producing magnocellular neurons, the effects of the expressed mutants on cell viability was examined. Initial studies showed that the growth rate of stably transfected neuro2A cells was unaffected by expression of either WT or mutant $A V P$ genes (data not shown). Neuro2A cell lines were also treated with VPA to induce differentiation and to more closely mimic the features of postmitotic neurons (28). VPA is known to inhibit the cell cycle in the G1 phase, at a point 6-6.5 h before $\mathrm{S}$ phase (29). Cells were treated with $1 \mathrm{mM} \mathrm{VPA}$ for $6 \mathrm{wk}$, and the number of viable cells was determined once a week using the MTS assay. Treatment with VPA did not alter the pattern of labeled AVP proteins in cells and the medium (data not shown). As shown in Fig. 3, the cell number in the lines expressing WT or CAT was 


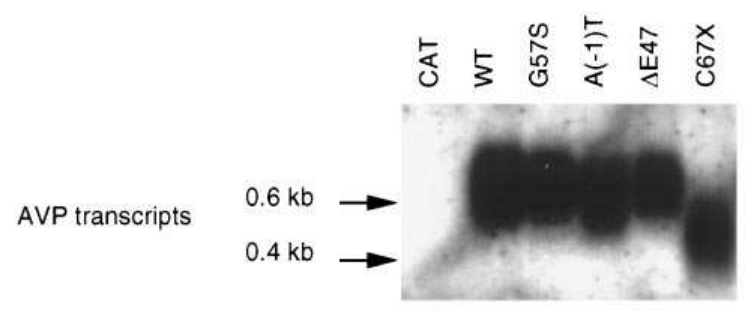

B

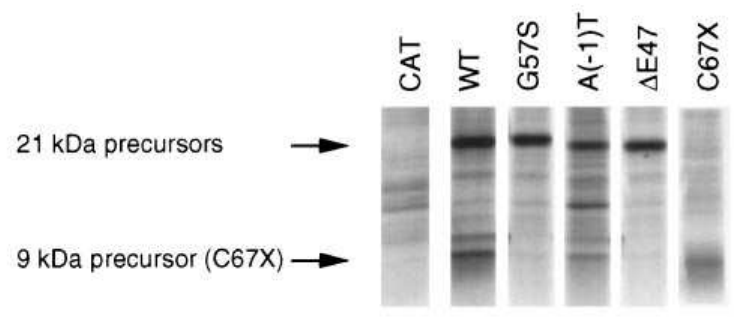

C

AVP immunoreactivity in the culture medium (pg/ $\mu \mathrm{g}$ of cell protein/24hr)

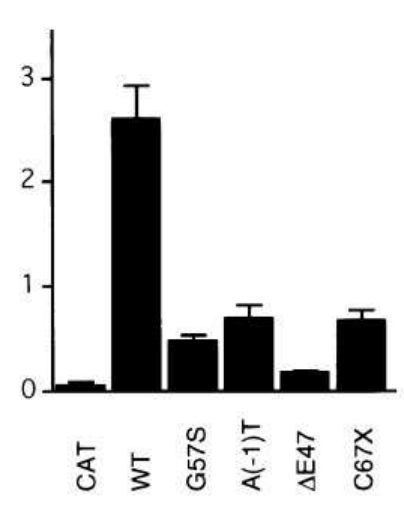

Figure 2. Expression of AVP mRNA and precursor proteins in stably transfected neuro2A cells. (A) Stably transfected clones were analyzed by Northern blot for $A V P$ gene expression using ${ }^{32} \mathrm{P}$-labeled full length human $A V P$ cDNA. Representative clones showing similar levels of $A V P$ transcripts are illustrated. Note that the C67X cDNA in the expression vector is smaller and expresses a transcript with reduced length $(0.4 \mathrm{~kb})$. (B) The clones shown in $A$ were continuously labeled with ${ }^{35} \mathrm{~S}$-methionine and cysteine and cell extracts were subjected to immunoprecipitation using an anti-NP antibody. The protein products were subjected to $16.5 \%$ SDS-PAGE and autoradiography. The positions of the $21-\mathrm{kD}$ precursor and the predicted $9-\mathrm{kD}$ precursor for the C67X mutant are indicated with arrows. $(C)$ The AVP immunoreactivity secreted into the medium for $24 \mathrm{~h}$ was measured by radioimmunoassay. The immunoreactivity is expressed as picogram AVP immunoreactivity/microgram of cell protein per $24 \mathrm{~h}$. Data represents mean \pm SD from triplicate wells.

unchanged over the 6-wk period of study. These findings confirm that VPA is cytostatic and demonstrate that overexpression of normal AVP precursor or CAT protein is not toxic. In contrast, viability was reduced in each of cell lines expressing the mutant $A V P$ genes. Cell loss was most prominent with the C67X mutant. Only $\sim 50 \%$ cells were viable after $1 \mathrm{wk}$ and nearly all cells were lost by $3 \mathrm{wk}$ of treatment. The viability of the cell lines expressing the other mutants was variable. After $5 \mathrm{wk}$, the rank order of cell loss was C67X $>\mathrm{A}(-1) \mathrm{T}>$ $\mathrm{G} 57 \mathrm{~S}>\Delta \mathrm{E} 47$.

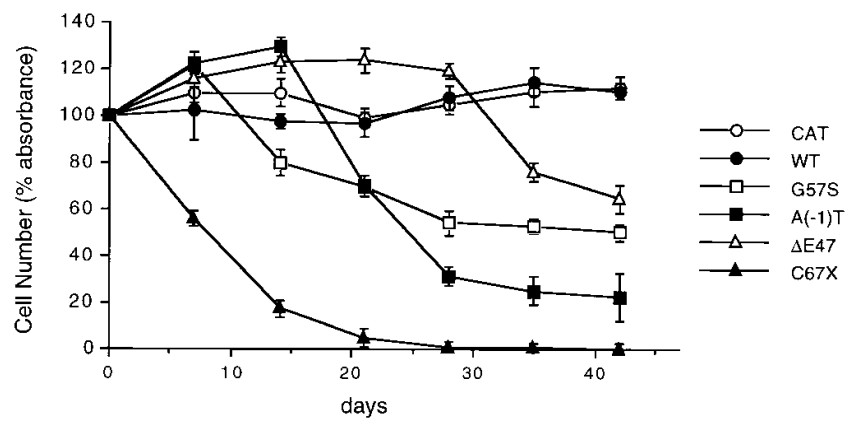

Figure 3. Effect of mutant AVP proteins on cell viability. Stable cell lines expressing the WT, the indicated mutants, or the CAT were divided into seven 96-well plates and treated with VPA $(1 \mathrm{mM})$ for 6 wk. Once a week $(0,1,2,3,4,5,6 \mathrm{wk})$, the number of viable cells in each well was determined using the MTS assay. The absorbance (490-630nm) is expressed as the percentage of the absorbance at the start of the experiment. Values are expressed as the mean \pm SD $(n=4)$.

The mechanism of cell death was investigated to determine whether cytotoxicity reflected necrosis or apoptosis. Light microscopic analysis of cells expressing the mutant AVP precursors did not show the morphological characteristics of cells undergoing apoptosis (data not shown) (30). In addition, there was no evidence for distinct DNA laddering or detection of fragmented DNA in individual cells using the in situ TUNEL assay (data not shown) (31). As a positive control, treatment of cells with DNase I demonstrated strong nuclear fluorescence. These results suggest that the toxic effects of mutant AVP protein in neuro2A cells involve a necrotic, rather than an apoptotic mechanism.

Posttranslational processing and intracellular trafficking of $W T$ and mutant AVP precursors in neuro $2 A$ cells. The observation that mutant AVP proteins are cytotoxic suggested the possibility that the posttranslational processing or intracellular trafficking of the proteins might be altered. Posttranslational processing was initially evaluated by performing immunoprecipitation of metabolically labeled proteins. Cell lines expressing WT or mutant AVP proteins were labeled continuously, and cell extracts and medium were harvested. Using the antiNP antibody, the WT cell extracts were shown to express 21$\mathrm{kD}$ precursor protein as well as 12- and 11-kD proteins (Fig. 4 $A$ ). The size of the precursor proteins was increased in the medium (major $22-\mathrm{kD}$ and minor $23-$ and $24-\mathrm{kD}$ proteins) relative to those in cell extracts. In the medium, the amount of $12-\mathrm{kD}$ protein was increased relative to the $11-\mathrm{kD}$ protein, which was predominant in the extracts. None of these proteins were detected in the control cells expressing CAT. To demonstrate which bands also contained the AVP peptide, an anti-AVP antibody was used (Fig. $4 \mathrm{~B}$ ). Each of the precursor forms that were detected with the anti-NP antibody were also immunoprecipitated by the anti-AVP antibody. Although the $12-\mathrm{kD}$ protein was recognized by anti-AVP antibody, the 11-kD protein was not, indicating that the $12-\mathrm{kD}$ protein is an intermediate form that contains both the AVP and NP domains, whereas the $11-\mathrm{kD}$ protein contains NP (Fig. $5 A$ ). The cleaved AVP peptide is too small $(1 \mathrm{kD})$ to be detected in these assays. To characterize the intracellular trafficking of precursors, immunoprecipitates were treated with Endo H. The $N$-linked oli- 
A

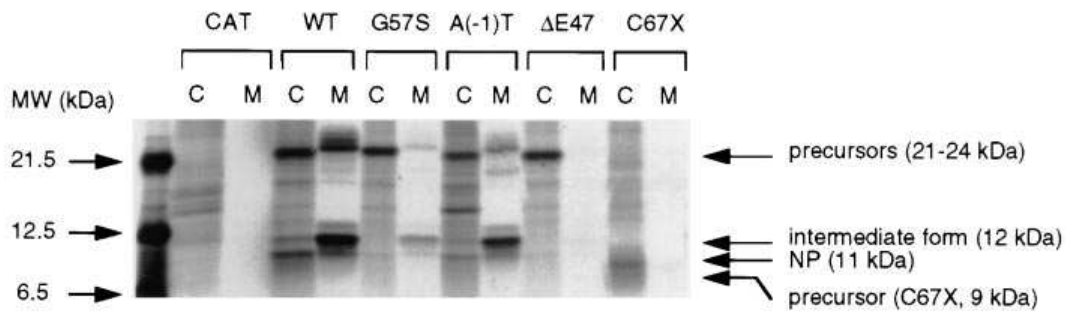

B

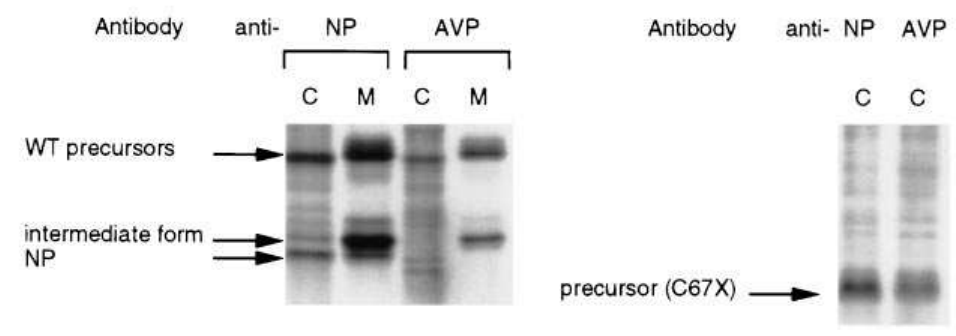

Figure 4. Analyses of synthesized AVP precursors in cells expressing wild-type and mutant proteins. $(A)$ Proteins in the stably transfected neuro2A clones were continuously labeled with ${ }^{35} \mathrm{~S}$-methionine and cysteine. Cell extracts $(C)$ (See Fig. $2 B$ ) and medium $(M)$ were subjected to immunoprecipitation using anti-NP antibody and proteins were analyzed by SDS-PAGE and autoradiography. The positions of the various proteins are indicated. $(B)$ The WT and C67X clones were continuously labeled and immunoprecipitation was performed using either anti-NP or AVP antibody. (C) Cell extracts and medium were subjected to immunoprecipitation using anti-NP antibody and the precipitated proteins were treated without or with Endo $\mathrm{H}$ to remove carbohydrates.

gosaccharides of glycoproteins are sensitive to Endo $\mathrm{H}$ while they are in the ER or in the early cis portions of the Golgi. When mannose residues of the oligosaccharides are cleaved in the medial Golgi, the glycoproteins become Endo $\mathrm{H}$ resistant, allowing the pattern of Endo $\mathrm{H}$ sensitivity to be used to monitor subcellular trafficking of newly synthesized glycoproteins through the ER and Golgi apparatus $(32,33)$. Using this approach, the intracellular 21-kD WT precursor was found to be Endo $\mathrm{H}$ sensitive, yielding a $17-\mathrm{kD}$ digested product (Fig. $4 \mathrm{C}$ ). In contrast, the precursors in the medium $(22-24 \mathrm{kD})$ were resistant to the Endo $\mathrm{H}$ digestion, consistent with the addition of carbohydrate side chains in the Golgi apparatus. Little or no Endo H-resistant precursors were detected in cells, suggesting that terminally glycosylated precursors in the Golgi apparatus are rapidly exported into the medium or undergo further processings. As expected, the more fully processed forms (12 and $11 \mathrm{kD}$ ) are Endo $\mathrm{H}$ resistant. To further evaluate the kinetics of conversion of AVP precursors into more fully processed forms, pulse-chase analyses were performed (Fig. 5 B). Most of the WT precursor were secreted into the medium upon glycosylation in the Golgi apparatus. However, a small fraction underwent proteolytic cleavage to the $12-\mathrm{kD}$ intermediate form, which was secreted by constitutive pathway. In contrast, further cleavage to AVP and 11-kD NP resulted in secretion of only a small amount of the 11-kD NP, suggesting that it is selectively stored in cells (Fig. $5 \mathrm{~A}$ ).
In the case of the G57S and $\Delta \mathrm{E} 47$ mutants, continuous labeling showed a marked reduction in the amount of precursors in the medium, and the $12-$ and $11-\mathrm{kD}$ forms were reduced in cells and the medium compared with WT (Fig. $4 A$ ). The $\mathrm{A}(-1) \mathrm{T}$ signal peptide mutation showed less production of these proteins compared with the WT. The relative abundance of these proteins varied among the different mutants $(\mathrm{A}(-1) \mathrm{T}>\mathrm{G} 57 \mathrm{~S}>\Delta \mathrm{E} 47)$. The $\mathrm{C} 67 \mathrm{X}$ truncation mutation resulted in an atypical 9-kD product which was also immunoprecipitated by anti-AVP antibody (Fig. 4 B), but there was little immunoreactive protein in the medium. The effects of Endo $\mathrm{H}$ were similar for WT and mutant (G57S, A(-1)T, $\Delta$ E47) AVP precursor proteins (Fig. $4 \mathrm{C}$ ). Because glycosylation of precursors in the Golgi apparatus appears to result in rapid secretion into the medium, this finding suggests that mutant $21-\mathrm{kD}$ precursors are not transported to the Golgi apparatus as effectively as the WT precursor. Pulse-chase studies revealed that mutant AVP precursors are processed and secreted less efficiently than the WT precursors (Fig. $5 \mathrm{~B}$ ). This was most pronounced with the G57S, $\Delta \mathrm{E} 47$, and C67X mutants. In the case of the $\mathrm{A}(-1) \mathrm{T}$ signal peptide mutant, there was more secretion of precursors and the $12-$ and $11-\mathrm{kD}$ forms into the medium compared with the other mutants. In addition, an aberrant $23-\mathrm{kD}$ protein was also detected in cells during the first $2 \mathrm{~h}$ after labeling (Fig. $5 \mathrm{~B}$, arrow). As depicted in Fig. $5 \mathrm{~A}$, this may correspond to a glycosylated precursor which retains the 


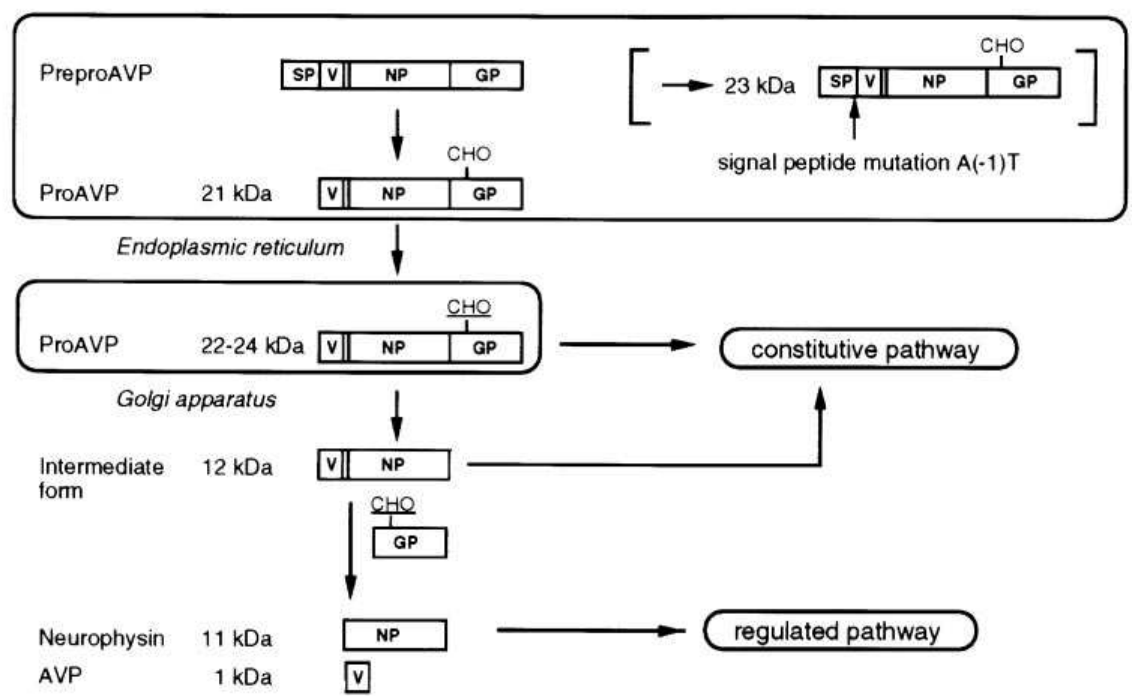

B

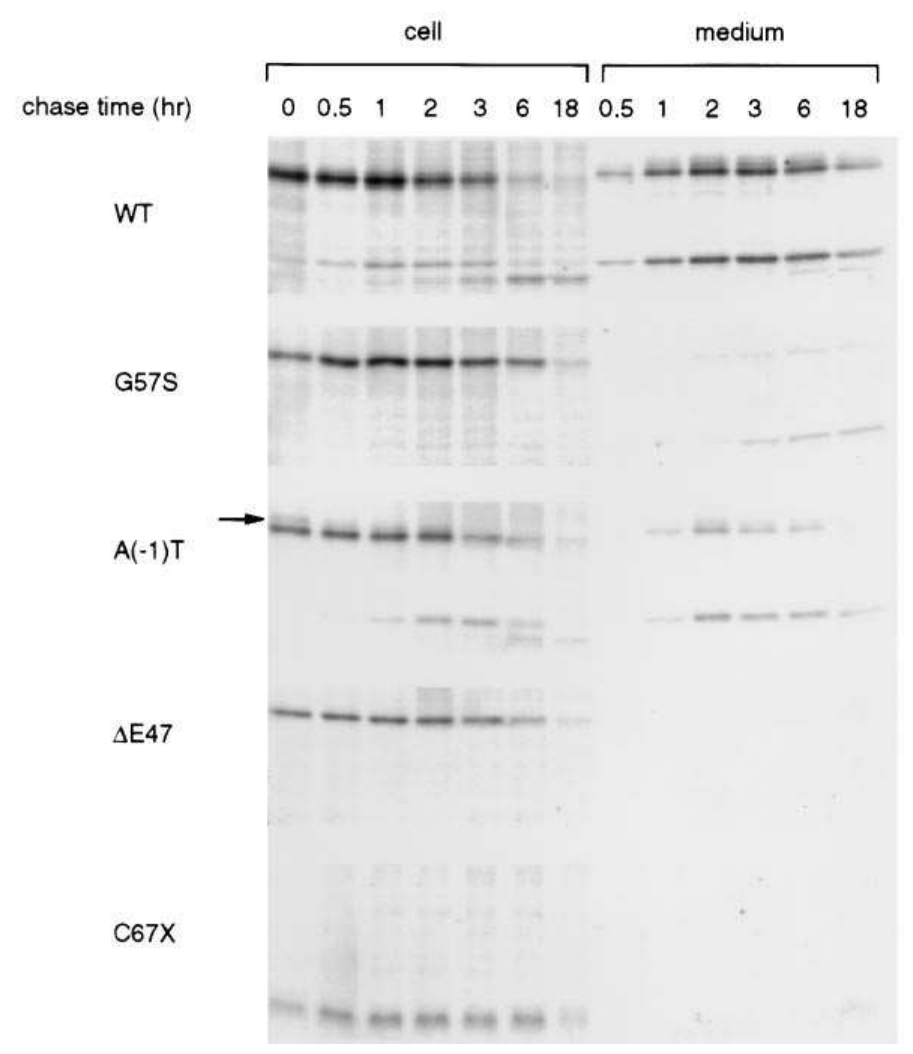

Figure 5. Pulse-chase analysis of wildtype and mutant AVP precursors in neuro2A cells. $(A)$ Schematic illustration of pathways for intracellular processing of AVP precursors. PreproAVP is converted to proAVP by removal of the signal peptide and the addition of carbohydrate within ER. ProAVP that is partially glycosylated within the ER $(21 \mathrm{kD})$ is glycosylated further within the Golgi apparatus (shown by the underline). The terminally glycosylated proAVP $(22-24 k D)$ is constitutively secreted into the medium or converted to the intermediate form consisting of the AVP and NP domains $(12 \mathrm{kD})$. The intermediate form is also secreted by constitutive pathway. Part of the intermediate form is processed into the AVP and NP molecules $(11 \mathrm{kD})$, both of which are stored in the tips of neuronal processes and secreted by the regulated pathway. Inefficient cleavage of the $\mathrm{A}(-1) \mathrm{T}$ precursor results in a $23-\mathrm{kD}$ aberrant precursor that is glycosylated, but is not cleaved by signal peptidase. $S P$, signal peptide; $V$, AVP; $N P$, neurophysin; $G P$, glycoprotein. (B) Stable cells for the WT and the indicated mutants were labeled for $0.5 \mathrm{~h}$ and chased for the indicated time. Cell extracts and the medium were subjected to the immunoprecipitation using anti-NP antibody. Arrow indicates a $23-\mathrm{kD}$ preproAVP that is glycosylated, but not cleaved by signal peptidase. signal peptide (10). Taken together, it is suggested that the intracellular trafficking of mutant AVP precursors from the ER to the Golgi apparatus is impaired, resulting in diminished processing of the precursor and AVP production.

Mutant precursors accumulate within the endoplasmic reticulum. Indirect immunofluorescence staining was used for cellular localization of AVP proteins. Using the anti-NP antibody, cells expressing the WT or the various mutant forms showed diffuse cytoplasmic staining which was not detected in cells expressing the control CAT protein (data not shown).
However, the WT also showed enhanced staining at the tips of cellular processes, and this was absent or less pronounced with the mutants (data not shown).

Immunofluorescence study was also performed after treatment of cells with VPA for 1 wk (Fig. 6). Under these conditions, the cell line expressing the WT showed intense fluorescence in the tips of processes (Fig. $6 \mathrm{~A}$ ). In contrast to the WT, each of the cell lines expressing mutant forms exhibited a large amount of punctate intracellular staining (Fig. 6, $B-E$ ). The accumulation of these intracellular aggregates varied, but was 

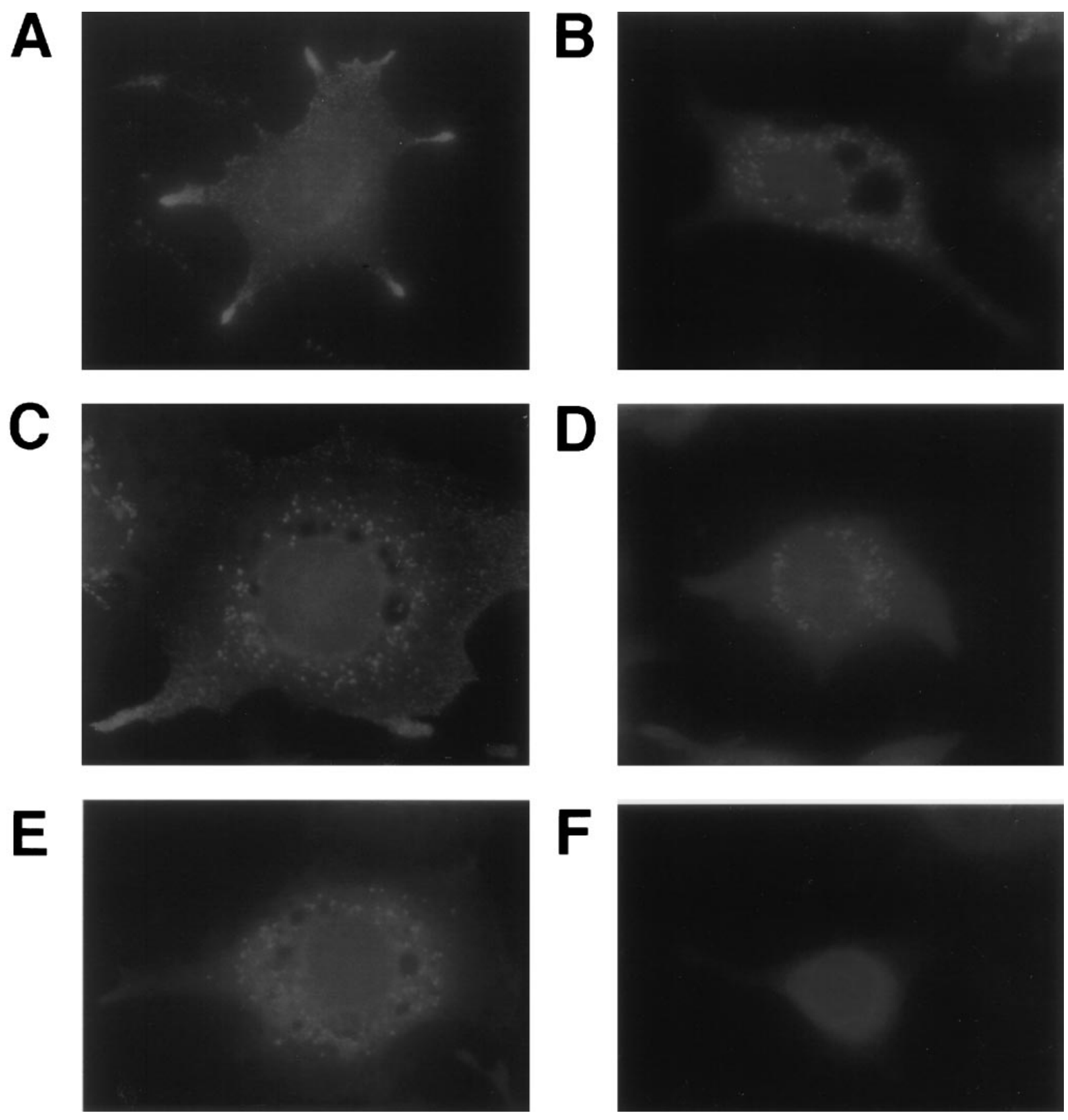

Figure 6. Indirect immunofluorescence staining. Stable cells for the WT, G57S, A(-1)T, $\Delta \mathrm{E} 47$, and C67X were grown on chamber slides, treated with VPA $(1 \mathrm{mM})$ for $1 \mathrm{wk}$ and stained with anti-NP antibody $(A, B, C, D$, and $E$, respectively). Stable cells for the WT were grown on chamber slides and stained with anti-KDEL antibody $(F)$.

the most prominent in the C67X clone. There was diminished staining in the terminal processes with mutants G57S, $\Delta \mathrm{E} 47$, and C67X. Although less intense than with the WT, the A(-1)T mutant produced moderate staining in terminal processes (Fig. $6 C$ ), consistent with greater production of NP molecules than with the other mutants. An anti-KDEL antibody, which recognizes the ER retention signal (Lys(K)-Asp(D)-Glu(E)-Leu(L)) that is present at the carboxyterminus of ER resident proteins, also demonstrated diffuse cytoplasmic staining (Fig. $6 F$ ).

\section{Discussion}

Several mechanisms might account for dominant mode of inheritance of FNDI. It is unlikely that the disorder results from loss of function of one of the two $A V P$ genes. In this circumstance, one might expect diminished AVP reserve in response to hyperosmotic stimuli, but it is unclear why this would cause progressive loss of function over time (13). In some dominant disorders, the pathophysiology involves the formation of inactive heterodimers (34). It is possible that WT and mutant proteins could interact with one another. The AVP peptide is known to bind to a pocket in NP (35), and the NP molecules have been shown to self-associate to form oligomer complexes $(36,37)$. Mutant AVP precursors, once bound to the normal precursors, could therefore form aggregates and impair the production of AVP from the normal allele. At present, there is no evidence to support such a model for mutant precursor action. 
The mechanism of FNDI has also been speculated to involve neuronal toxicity. Several lines of evidence support this idea. First, the clinical onset of the disease is delayed, and is progressive during early childhood (13). Thus, it appears that some children with FNDI are born with normally functioning AVP-producing neurons, but lose this activity over time. Second, in vivo imaging studies (17), and autopsy studies (19-21) are consistent with selective loss of AVP neurons and their axonal extensions into the neurohypophysis. Third, the $\mathrm{A}(-1) \mathrm{T}$ signal peptide mutation resulted in an abnormally processed precursor protein in vitro (10), which was postulated to be accumulated within the ER and cytotoxic. In this study, we found that each of the four different AVP mutants studied caused reduced cell viability when studied in neuro2A cells (Fig. 3). In addition, we examined the hypothesis that the mutant forms of AVP precursors are accumulated within the ER, providing a potential mechanism for cell toxicity.

Neuro2A cells were chosen for this study because they are of neuronal origin and because it is possible to induce differentiation by treatment with VPA. Analogous studies were also attempted in human teratocarcinoma cell line, NT2 cells, which can be differentiated into postmitotic neurons by retinoic acid, but stably transfected clones were not isolated despite several attempts (data not shown). The level of expression of the WT and mutant $A V P$ genes in the neuro2A cells was matched as closely as possible in the different clonal isolates. Clones were selected initially based upon the levels of $A V P$ mRNA expression (Fig. $2 A$ ). Although the amounts of metabolically labeled precursor protein were similar (except for the truncated protein C67X) (Fig. 2 B), there was diminished secretion of immunoreactive AVP in each of the mutant clones (Fig. $2 C$ ). As shown by metabolic labeling (Figs. 4 and $5 B$ ), the diminished secretion likely reflects defective intracellular trafficking of precursors to the Golgi apparatus.

Although expression of the mutants caused little or no alteration in the viability of rapidly proliferating neuro2A cells, inhibition of mitosis and induction of differentiation by treatment with VPA allowed demonstration of the toxic effects of AVP precursor mutants (Fig. 3). It is notable that cytotoxicity was relatively slow in onset and varied among the different mutants $(\mathrm{C} 67 \mathrm{X}>\mathrm{A}(-1) \mathrm{T}>\mathrm{G} 57 \mathrm{~S}>\Delta \mathrm{E} 47)$. As shown by immunofluorescence staining with the anti-NP antibody, VPA treatment was accompanied by punctate intracellular staining (Fig. 6). The accumulated immunoreactive NP proteins were colocalized with the ER resident proteins that were detected with an anti-KDEL antibody. The pattern of punctate staining was specific for the AVP mutants, although the abundance varied among the different mutants $(\mathrm{C} 67 \mathrm{X}>\mathrm{G} 57 \mathrm{~S}>\mathrm{A}(-1) \mathrm{T}>$ $\Delta \mathrm{E} 47)$. In contrast, the VPA-treated WT clone exhibited diffuse staining throughout the cytoplasm and lacked the punctate staining in the ER region.

The $\Delta \mathrm{E} 47$ mutant precursors appear to be entirely arrested within the ER (Figs. $2 C, 4 A$, and $5 B$ ). However, both the punctate staining and cytotoxicity with the $\Delta \mathrm{E} 47$ mutant were less than those seen with the other mutants. Most of unfolded or incompletely folded proteins that are retained within the ER are subjected to degradation by a nonlysosomal proteolytic pathway. The $\Delta \mathrm{E} 47$ mutant precursors may be readily degraded by this system thereby precluding accumulation of the precursors within the ER, resulting in less profound cytotoxicity. It appears that cell survival depends on how effectively cells are able to degrade unfolded or incompletely folded proteins. The more the degradation-resistant proteins are retained within the ER, the more profound the cytotoxic effect. It would be interesting to examine whether there is a correlation between the effects of different mutations on cell viability and the severity or rate of onset of diabetes insipidus, but this will require more thorough evaluation of clinical phenotypes.

The phenomenon of cytotoxicity caused by the accumulation of mutant precursors has been proposed previously for other genetic disorders. Other examples of autosomal dominant hormone deficiency syndromes include mutations in growth hormone (38) and in the signal sequence of parathyroid hormone (39). In each of these cases, accumulation and toxicity of the mutant hormone has been speculated to lead to cellular toxicity.

The model of $\alpha 1$-antitrypsin deficiency has been studied extensively. The PiZ variant of human $\alpha 1$-antitrypsin is associated with decreased levels of the protein in sera as a result of retention within hepatocytes (40). The variant form is retained within the ER in patients with the disease, and in PiZ-bearing transgenic mice $(41,42)$. Although most of the $\mathrm{PiZ}$ variant is degraded (43), the reminder aggregates to form insoluble inclusions that are resistant to degradation and accumulate gradually within the distended cisternae of the ER (44). The degree of liver damage correlates with the amount of the PiZ variant in different pedigrees of mice (42). In some forms of Alzheimer's disease, amyloid $\beta$ protein is responsible for the neurodegeneration, and the formation of amyloid aggregates has been proposed to cause neurotoxicity $(45,46)$.

In summary, we have provided evidence that mutant AVP precursors induce neuronal cell death as a result of their accumulation within the ER, suggesting that the pathogenesis of FNDI may be caused by cytotoxicity of mutant precursors. This hypothesis could account for the delayed onset and autosomal dominant mode of inheritance of the disease. Future studies in transgenic models should allow the molecular mechanisms of defective intracellular trafficking and cytotoxicity to be examined further in vivo.

\section{Acknowledgments}

We are grateful to Yutaka Oiso and Hiroshi Nagasaki (First Department of Internal Medicine, Nagoya University School of Medicine, Japan) for measuring AVP immunoreactivity. We thank Gary Robertson, Wen-Xia Gu, Richard Yu, and Joanne McAndrews for helpful discussions.

\section{References}

1. Baylis, P.H. 1995. Vasopressin and its neurophysin. In Endocrinology. L.J. DeGroot, editor. W.B. Saunders \& Co., Philadelphia. 406-420.

2. Robertson, G.L., and T. Berl. 1995. Pathophysiology of water metabolism. In Disturbances in Control of Body Fluid Volume and Composition. B.M. Brenner and R.C. Rector, editors. W.B. Saunders \& Co., Philadelphia. 873-928.

3. Brownstein, M.J., J.T. Russel, and H. Gainer. 1980. Synthesis, transport, and release of posterior pituitary hormones. Science (Wash. DC). 207:373-378.

4. Riddell, D.C., R. Mallonee, J.A. Phillips, J.S. Parks, L.A. Sexton, and J.L. Hamerton. 1985. Chromosomal assignment of human sequences encoding arginine vasopressin-neurophysin II and growth hormone releasing factor. Somatic Cell Mol. Genet. 11:189-195.

5. Sausville, E., D. Carney, and J. Battey. 1985. The human vasopressin gene is linked to the oxytocin gene and is selectively expressed in a cultured lung cancer cell line. J. Biol. Chem. 260:10236-10241.

6. Ito, M., Y. Mori, Y. Oiso, and H. Saito. 1991. A single base substitution in the coding region for neurophysin II associated with familial central diabetes insipidus. J. Clin. Invest. 87:725-728.

7. Baylis, P.H., and G.L. Robertson. 1981. Vasopressin function in familial cranial diabetes insipidus. Postgrad. Med. J. 57:36-40. 
8. Kaplowitz, P.B., A.J. D'Ercole, and G.L. Robertson. 1982. Radioimmunoassay of vasopressin in familial central diabetes insipidus. J. Pediatr. 100:7681.

9. Bahnsen, U., P. Oosting, D.F. Swaab, P. Nahke, D. Richter, and H. Schmale. 1992. A missense mutation in the vasopressin-neurophysin precursor gene cosegregates with human autosomal dominant neurohypophyseal diabetes insipidus. EMBO (Eur. Mol. Biol. Organ.) J. 11:19-23.

10. Ito, M., Y. Oiso, T. Murase, K. Kondo, H. Saito, T. Chinzei, M. Racchi, and M.O. Lively. 1993. Possible involvement of inefficient cleavage of preprovasopressin by signal peptidase as a cause for familial central diabetes insipidus. J. Clin. Invest. 91:2565-2571.

11. Yuasa, H., M. Ito, H. Nagasaki, Y. Oiso, S. Miyamoto, N. Sasaki, and H. Saito. 1993. Glu-47, which forms a salt bridge between neurophysin-II and arginine vasopressin, is deleted in patients with familial central diabetes insipidus. J. Clin. Endocrinol. Metab. 77:600-604.

12. Krishnamani, M.R., J.A.I. Phillips, and K.C. Copeland. 1993. Detection of a novel arginine vasopressin defect by dideoxy fingerprinting. J. Clin. Endocrinol. Metab. 77:596-598.

13. McLeod, J.F., L. Kovacs, M.B. Gaskill, S. Rittig, G.S. Bradley, and G.L. Robertson. 1993. Familial neurohypophyseal diabetes insipidus associated with a signal peptide mutation. J. Clin. Endocrinol. Metab. 77:599A-599G.

14. Repaske, D.R., and J.E. Browning. 1994. A de novo mutation in the coding sequence for neurophysin-II (Pro24 $\rightarrow$ Leu) is associated with onset and transmission of autosomal dominant neurohypophyseal diabetes insipidus. $J$. Clin. Endocrinol. Metab. 79:421-427.

15. Nagasaki, H., M. Ito, H. Yuasa, H. Saito, M. Fukase, K. Hamada, E. Ishikawa, H. Katakami, and Y. Oiso. 1995. Two novel mutations in the coding region for neurophysin-II associated with familial central diabetes insipidus. $J$. Clin. Endocrinol. Metab. 80:1352-1356.

16. Rittig, S., G.L. Robertson, C. Siggaard, L. Kovacs, N. Gregerse, J. Nyborg, and E.B. Pedersen. 1996. Identification of 13 new mutations in the vasopressin-neurophysin II gene in 17 kindreds with familial autosomal dominant neurohypophyseal diabetes insipidus. Am. J. Hum. Genet. 58:107-117.

17. Rutishauser, J., M. Boni-Schnetzler, J. Boni, W. Wichmann, T. Huisman, M.B. Vallotton, and E.R. Froesch. 1996. A novel point mutation in the translation initiation codon of the pre-pro-vasopressin-neurophysin II gene: cosegregation with morphological abnormalities and clinical symptoms in autosomal dominant neurohypophyseal diabetes insipidus. J. Clin. Endocrinol. Metab. 81:192-198.

17a. Rittig, S., C. Siggaard, M. Ozata, I. Yetkin, M.A. Gundogan, G.L. Robertson, and E.B. Pedersen. 1996. Familial neurohypophyseal diabetes insipidus due to mutation that substitutes histidine for tyrosine- 2 in the antidiuretic hormone. Central Society for Clinical Research. 387a. (Abstr.)

18. Ueta, Y., S. Taniguchi, A. Yoshida, I. Murakami, Y. Mitani, I. Hisatome, I. Manabe, R. Sato, M. Tsuboi, A. Ohtahara, et al. 1996. A new type of familial central diabetes insipidus caused by a single base substitution in the neurophysin II coding region of the vasopressin gene. J. Clin. Endocrinol. Metab. 81:1787-1790.

19. Braverman, L.E., J.P. Mancini, and D.M. McGoldrick. 1965. Hereditary idiopathic diabetes insipidus: a case report with autopsy findings. Ann. Intern. Med. 63:503-508.

20. Nagai, I., C.H. Li, S.M. Hsieh, T. Kizaki, and Y. Urano. 1984. Two cases of hereditary diabetes insipidus, with an autopsy finding in one. Acta. Endocrinol. 105:318-323.

21. Bergeron, C., K. Kovacs, C. Ezrin, and C. Mizzen. 1991. Hereditary diabetes insipidus: an immunohistochemical study of the hypothalamus and pituitary gland. Acta. Neuropathol. 81:345-348.

22. Ross, J., J.B. Olmsted, and J.L. Rosenbaum. 1975. The ultrastructure of mouse neuroblastoma cells in tissue culture. Tissue Cell. 7:107-135.

23. Noel, G., L. Zollinger, F. Laliberte, E. Rassart, P. Crine, and G. Boileau. 1989. Targeting and processing of pro-opiomelanocortin in neuronal cell lines. J. Neurochem. 52:1050-1057.

24. Chevrier, D., H. Fournier, C. Nault, M. Zollinger, P. Crine, and G. Boileau. 1991. Expression of porcine pro-opiomelanocortin in mouse neuroblastoma (Neuro2A) cells: targeting of the foreign neuropeptide to dense-core ves- icles. Mol. Cell. Endocrinol. 79:109-118.

25. de Bree, F.M., and J.P. Burbach. 1994. Heterologous biosynthesis and processing of preprovasopressin in Neuro2A neuroblastoma cells. Biochimie (Paris). 76:315-319.

26. Sanger, F., S. Nicklen, and A.R. Coulson. 1977. DNA sequencing with chain-terminating inhibitors. Proc. Natl. Acad. Sci. USA. 74:5463-5467.

27. Burman, S., D. Wellner, B. Chait, T. Chaudhary, and E. Breslow. 1989. Complete assignment of neurophysin disulfides indicates pairing in two separate domains. Proc. Natl. Acad. Sci. USA. 86:429-433.

28. Regan, C.M. 1985. Therapeutic levels of sodium valproate inhibit mitotic indices in cells of neural origin. Brain Res. 347:394-398.

29. Martin, M.L., and C.M. Regan. 1991. The anticonvulsant valproate teratogen restricts the glial cell cycle at a defined point in the mid-G1 phase. Brain Res. 554:223-228.

30. Wyllie, A.H., J.F. Kerr, and A.R. Currie. 1980. Cell death: the significance of apoptosis. Int. Rev. Cytol. 68:251-306.

31. Bursch, W., S. Paffe, B. Putz, G. Barthel, and R. Schulte-Hermann. 1990. Determination of the length of the histological stages of apoptosis in normal liver and in altered hepatic foci of rats. Carcinogenesis (Eynsham). 11:847853.

32. Rothman, J.E., and L. Orci. 1990. Movement of proteins through the Golgi stack: a molecular dissection of vesicular transport. FASEB J. 4:14601468 .

33. Mellman, I., and K. Simons. 1992. The Golgi complex: in vitro veritas? Cell. 68:829-840.

34. Herskowitz, I. 1987. Functional inactivation of genes by dominant negative mutations. Nature (Lond.). 329:219-222.

35. Chen, L.Q., J.P. Rose, E. Breslow, D. Yang, W.R. Chang, W.F.J. Furey, M. Sax, and B.C. Wang. 1991. Crystal structure of a bovine neurophysin II dipeptide complex at 2.8 A determined from the single-wavelength anomalous scattering signal of an incorporated iodine atom. Proc. Natl. Acad. Sci. USA. 88 4240-4244.

36. Rholam, M., P. Nicolas, and P. Cohen. 1982. Binding of neurohypophyseal peptides to neurophysin dimer promotes formation of compact and spherical complexes. Biochemistry. 21:4968-4973

37. Fassina, G., and I.M. Chaiken. 1988. Structural requirements of peptide hormone binding for peptide-potentiated self-association of bovine neurophysin II. J. Biol. Chem. 263:13539-13543.

38. Cogan, J.D., B. Ramel, M. Lehto, J.R. Phillips, M. Prince, R.M. Blizzard, T.J. de Ravel, M. Brammert, and L. Groop. 1995. A recurring dominant negative mutation causes autosomal dominant growth hormone deficiency-a clinical research center study. J. Clin. Endocrinol. Metab. 80:3591-3595.

39. Arnold, A., S.A. Horst, T.J. Gardella, H. Baba, M.A. Levine, and H.M. Kronenberg. 1990. Mutation of the signal peptide-encoding region of the preproparathyroid hormone gene in familial isolated hypoparathyroidism. J. Clin. Invest. 86:1084-1087.

40. Ganrot, P.O., C.B. Laurell, and S. Eriksson. 1967. Obstructive lung disease and trypsin inhibitors in alpha-1-antitrypsin deficiency. Scand. J. Clin. Lab. Invest. 19:205-208.

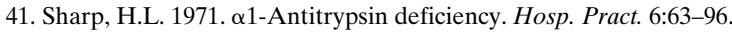

42. Carlson, J.A., B.B. Rogers, R.N. Sifers, M.J. Finegold, S.M. Clift, F.J. DeMayo, D.W. Bullock, and S.L. Woo. 1989. Accumulation of PiZ alpha 1-antitrypsin causes liver damage in transgenic mice. J. Clin. Invest. 83:1183-1190.

43. Le, A., K.S. Graham, and R.N. Sifers. 1990. Intracellular degradation of the transport-impaired human PiZ a1-antitrypsin variant. J. Biol. Chem. 265: $14001-14007$.

44. Lomas, D.A., D.L. Evans, J.T. Finch, and R.W. Carrell. 1992. The mechanism of $\mathrm{Z}$ alpha 1-antitrypsin accumulation in the liver. Nature (Lond.). 357:605-607.

45. Iversen, L.L., R.J. Mortishire-Smith, S.J. Pollack, and M.S. Shearman. 1995. The toxicity in vitro of beta-amyloid protein. Biochem. J. 311:1-16.

46. LaFerla, F.M., B.T. Tinkle, C.J. Bieberich, C.C. Haudenschild, and G. Jay. 1995. The Alzheimer's A beta peptide induces neurodegeneration and apoptotic cell death in transgenic mice. Nature Genet. 9:21-30. 